REVISTA CHILENA DE LITERATURA

Abril 2010, Número 76, 93 - 104

\title{
"ESCRUPULARIO"Y RESILENCIA EN VEINTE POEMAS DE AMOR Y UNA CANCIÓN DESESPERADA DE PABLO NERUDA ${ }^{1}$
}

\author{
Yanko González \\ Universidad Austral de Chile \\ ygonzale@uach.cl
}

RESUMEN / ABSTRACT

Veinte Poemas de Amor y Una Canción Desesperada (1924) de Pablo Neruda es uno de los libros cardinales de la sociabilidad lírica y la educación sentimental hispanoamericana. Aunque la obra ha sido ampliamente escrutada y examinada -convertido ya el documento en "monumento"-, tanto el proceso generativo como su correlato sociocrítico no han sido suficientemente ponderados para abordar los dispositivos y procedimientos que co-construyen la segunda publicación del vate. A partir de referentes biobibliográficos, críticos e históricos, este trabajo pretende explorar sintéticamente las estrategias textuales, estéticas y socioculturales que se articulan en la factura de Veinte Poemas de Amor... proponiendo una lectura que enfatiza la exhaustividad autocrítica del autor y las paradojas valorativas de la obra a la luz de su recepción en Chile.

Palabras Clave: Neruda, poesía, Veinte Poemas de Amor y Una Canción Desesperada, estrategia textual, estrategia estética, resilencia.

Pablo Neruda's Twenty Love Poems and a Song of Despair (1942) is one of the cardinal books of Spanish American lyric sociability and sentimental education. Though this work has been widely scrutinized and examined-turned from document into "monument"- both its generative process and sociocritical correlative context have not been sufficiently pondered in order to tackle the mechanisms and procedures that co-construct its second published

1 Este trabajo tuvo su origen en un prólogo al libro homónimo reeditado por ediciones UDP el año 2008. 
edition by the poet. From bio-bibliographical, critical, and historical references, this article attemps to synthetically explore the textual, aesthetic and sociocultural strategies articulated in Twenty Love Poems 'manufacture, proposing an interpretation that emphasizes the author's self-critical exhaustivety, and the paradoxes of this work's valuation, especially considering its reception in Chile.

KEY WORDS: Neruda, poetry, Twenty Love Poems and a Song of Despair, textual strategy, aesthetic strategy, resilience.

Veinte Poemas de Amor y Una Canción Desesperada $(1924)^{2}$ de Pablo Neruda es uno de los libros cardinales de la sociabilidad lírica y la educación sentimental hispanoamericana. Aunque la obra ha sido ampliamente escrutada y examinada-convertido ya el documento en "monumento" 3 -, tanto el proceso generativo como su correlato sociocrítico no han sido suficientemente ponderados para abordar los dispositivos y procedimientos que co-construyen la segunda publicación del vate. A partir de referentes biobibliográficos, críticos e históricos, este trabajo pretende explorar sintéticamente las estrategias textuales, estéticas y socioculturales que se articulan en la factura de Veinte Poemas de Amor ... proponiendo una lectura que enfatiza la exhaustividad autocrítica del autor y las paradojas valorativas de la obra a la luz de su recepción en Chile.

2 Como veremos, el año 1924 se publica la primera edición de la obra y en 1932 se imprime su versión definitiva. Los poemas citados en el presente trabajo -salvo que se indique lo contrario-, corresponden a ésta última versión reeditada en Chile en 2008 por ediciones UDP.

3 Entre muchos estudios específicos, se cuentan: Santander, Carlos. "Amor y temporalidad en Veinte poemas de amor". Anales de la Universidad de Chile. 157-160 (1971): 91-105; Loyola, Hernán. "Lectura de Veinte poemas de amor". Isaac Levy y Juan Loveluck, eds. Simposio Pablo Neruda: Actas. Nueva Cork: Las Américas, 1975. 339-353.; Morelli, Gabrielle. Strutture e lessico nei Veinte poemas de amor y una canción desesperada. Milán: Cisalpino-Goliardica, 1979; Yanko, Aroní. Pasión y abstracción en Veinte poemas de amor y una canción desesperada. Madrid: Editora Nacional, 1980; Lozada, Alfredo. "La amada crespuscular. Veinte poemas de amor y una canción desesperada". E. Rodríguez Monegal y E. Mario Sentí, eds. Pablo Neruda. Madrid: Taurus, 1980. 92-103. Araya, Guillermo. "Veinte poemas de amor y una canción desesperada". Bulletin Hispanique. 1-2/ 84 (1982): 145-186; Ellis, Keith. "La búsqueda infructuosa en Veinte poemas de amor y una canción desesperada". Nuevas aproximaciones a Pablo Neruda. México: FCE, 1987. 53-62; Morelli, Gabriele. Cómo leer Veinte poemas de amor de Pablo Neruda. Madrid: Júcar, 1997. 


\section{I. "ESCRUPULARIO"}

Sucede, de lectura en lectura, que el primer temblor al que invita Veinte Poemas..., no es sentimental, sino pedagógico. Oblicua pedagogía -ni sermón, ni cantinela: solo voces en sordina cuyo eco sugiere que la musa, ni inspirada, ni transpirada es finalmente, aun en el tránsito más aciago, escrupulosa corrección y curatoría.

A lo largo de 1923 y, sobre todo en el verano de 1924 a orillas del río Imperial, de Puerto Saavedra y de Carahue, aún de 19 años de edad y un solo libro publicado, el escalpelo de Ricardo Eliecer Neftalí Reyes Basoalto -ya convertido en Pablo Neruda- está para cirugías mayores. Escrito y ensamblado, teniendo como imaginario emocional a "Marisol" -Teresa Vásquez-, amor de la Frontera, en Temuco, "que impregna mi adolescencia provinciana"(Neruda, Conferencia $\mathrm{s} / \mathrm{n}$ ); a su compañera de curso del Instituto Pedagógico, "Marisombra" -Albertina Rosa Azócar Soto-, que la "aguardaba más tarde en el laberinto de Santiago" (Neruda, Conferencia $\mathrm{s} / \mathrm{n}$ ) y, marginalmente, a María Parodi, la de los "ojos negros y repentinos" (Neruda, Para Nacer 389) de Puerto Saavedra -inspiradora del poema 19-, la atribulada arquitectura de Veinte Poemas de Amor y Una Canción Desesperada no se funda solo en la congoja doliente del joven que ha desenclaustrado el deseo y se autoflajela con desmedidos golpes de frustración amatoria y despecho catártico. Programático, tras el tajo sentimental y la miseria sexual, se esconde un armazón "desesperadamente" calculado para extender un dolor que sabe occidental y globalizable, cuyos ingredientes residuales son una onza de heterosexualidad masculinizante y una pizca de monogamia fingidora agitadas en la dramaturgia del yo. De este modo, el problema de la recepción, de la interpelación y lectoría, estaba resuelto antes del erotizado poema 1: "Cuerpo de mujer, blancas colinas, muslos blancos, te pareces al mundo en tu actitud de entrega/ Mi cuerpo de labriego salvaje te socava..."(23), habida cuenta de un correlato histórico y cultural -al menos en Chile- en que las articulaciones de clase, género y generación explicaban una osada y ácrata liberación del parlamentarismo conservador -triunfo de Alessandri en 1920 vehiculizado por una juventud transformada en novísimo actor social-, y una tímida pero naciente oposición a la "oligarquía de los cuerpos" controlada por el ethos católico, porfiadamente anticlerical y con amplia reverberación crítica en la naciente mesocracia, de la que Neruda era un curioso, pero aventajado representante. 
En este contexto resulta axial el imaginario que irradia la Federación de Estudiantes de Chile (FECH), orgánica en la que Neruda participó como estudiante secundario y universitario. La FECH produjo y puso en circulación un espacio de identificación simbólico-juvenil gravitante para el momento, las llamadas "Fiestas de la Primavera" -realizadas en el mes de octubre de cada año-, que condensarán gran parte de las subjetividades juveniles en su versión mesocrática, estudiantil y masculina, por donde transitan prácticas e ideas sobre la emotividad y las relaciones amorosas cada vez más alejadas y opuestas al velo y la represión moral. La fiesta -que tuvo continuidad durante décadas- aglutinaba a la mayor parte de la expresión artística de la "bohemia" y donde tendía a visibilizarse tenuemente a algunas mujeresjóvenes, nomenclatura casi ausente por el monopolio de la tríada hombrejoven-estudiante con que había emergido el prototipo identitario juvenil a principios del siglo XX (González 65-74). En este sentido, parte del correlato sociocultural acompaña progresivamente el riesgo "moral" y expresivo de Veinte Poemas... en la medida, como lo plantea Schopf, en que "los poemas comunicaban una experiencia erótica y una imagen de la mujer y las relaciones amorosas hasta ese momento inéditas en la poesía chilena y, en general, en la poesía de la lengua española" (78).

De esta manera, el entuerto a resolver por Neruda se desplazaba de los niveles tópicos a los estéticos y, a su vez, de los meramente textuales a los contextuales. Es allí donde demuestra, temprano y certero, su talento y de paso, su pedagogía. Prueba, testea, en un ejercicio de matemática social, el parecer de mediadores y productores calificados para instalar un nuevo libro. Con Crepusculario (1923), había hecho lo propio -ayudándole a financiar la edición nada menos que el crítico Hernán Díaz Arrieta (Alone)-, sin embargo, había flaqueado en sus pretensiones mayores debido a su breve trayectoria e ilustración estética. El plan, ahora, contempla además de las estrategias sociales en el campo de fuerzas literario, hipótesis estilísticas. Coteja sus versos entre otros, con Aliro Oyarzún, Álvaro Yáñez (Juan Emar) y Alberto Rojas Jiménez, amigos, omnívoros lectores y, en el caso de Rojas Jiménez, vaso comunicante con el ultraísmo peninsular y la vanguardia francesa (particularmente con Guillaume Apollinaire). Se cartea con el poeta uruguayo Carlos Sabat Ercasty y el mismo Alone; anticipa en revistas-Claridad, Zig-Zag, entre otras-, una buena porción de textos, calibrando clínicamente su impacto. Toma una decisión crucial: debido a su intercambio epistolar con Sabat Ercasty decide posponer la publicación de un corpus paralelo a Veinte Poemas... titulado el "Hondero Entusiasta", que representaba para 
el vate -hasta ese momento- una muesca más contundente en la breve genealogía de su obra. Ecualiza su voz y se repliega sobre un trazo menos fuerte (Loyola, Neruda 155-158), pero menos replicante en el contexto de la poesía latinoamericana, escrutando y desbrozando el surco de sus textos sentimentales abiertos en el sur fluvial y en el cité metropolitano.

De este modo, vuelve contumaz sobre el proyecto de Veinte Poemas... Compone, refina y complejiza por la vía de la reducción; dota de inteligibilidad a la hipérbole o la metonimia hermética maridándola con el adjetivo llano, transparente. Cuela el tropo obvio para lograr una metáfora neutra, pero incandescente. Modula el riesgo, aquilatando la herencia casi monopólica del canon versificador -que asegura su recepción en la "gran" minoría lectoracon el atrevimiento de la textualidad sobremoderna: "sólo guardas tinieblas, hembra distante y mía, // de tu mirada emerge a veces, la costa del espanto" (Neruda 35; poema 7). Más aún, borronea autorías, en la seguridad culterana de la paráfrasis y la finitud de la originalidad, exprimiendo el poema "El Jardinero" de Rabindranath Tagore, para dejar un sumo destilado, aunque todavía dulzón, que es el poema 16: "mi alma nace a la orilla de tus ojos de luto. // En tus ojos de luto comienza el país del sueño" (53). Mismo poematrampa que hizo que sus enemigos literarios lo acusaran de plagio.

Neruda desecha la anécdota remilgada y biográfica que empaña no solo la eficacia comunicativa, sino estética. Conocida es su radical enmienda al poema 15, anticipado doblemente, tanto en la revista Vendimia de La Serena -noviembre de 1923-, como en la revista Zig-Zag, ambos bajo el literal y naif título "Poesía de su silencio". En una de sus podas capitales, el poeta elimina una estrofa completa del texto original que seguía a la cuarta estrofa (de la que, por cierto, extrae y sustituye los versos tercero y cuarto). El bardo recela, vergonzante y frío, de publicar bajo el prestigiado y elítico soporte libro, esta licencia inexcusable: "como callabas antes cuando eras más pequeña? // Así se te quedaban las manos sobre el pecho?) // (Si tú no me lo dices tendré que preguntárselo // a tu hermano el poeta que se fue para México" (Neruda, Poesía s/n).

Más aún, el manuscrito de lo que sería el poema 15 titulado "poema de su silencio" y subtitulado "mariposa de sueño" -atesorado por Albertina Azócar ${ }^{4}-$, señala, igualmente, múltiples correcciones y reelaboraciones,

4 Manuscrito dirigido a Albertina Azócar y publicado en formato facsimilar por Fernández, Sergio. Cartas de Amor de Pablo Neruda. 
entre las que se encuentra la factura de la rítmica y astuta última estrofa: "Y estoy alegre, alegre de que no sea cierto" (51). Como lo consigna Hernán Loyola, pocos manuscritos testimonian la "batalla para superar los límites y obstáculos (...) un salto de calidad poética sorprendido en su actuación misma. Nada mal tratándose de un muchacho de 19 años" (Loyola, Notas 54). Lo cierto es que Neruda en 1924 era biológicamente joven, pero social y literariamente adulto, con la capacidad e inteligencia de trazar una "táctica estética", un plan estilístico depurado que le permitiera situarse en los intersticios del modernismo y postmodernismo poético criollo, con flecos y borlas propias.

Como lo anticipábamos, el autor tiene, al menos, una triple tribulación: la lejanía y frialdad insufrible de "Marisombra" - la de la "boina gris"-; el recuerdo provincial y anhelante de "Marisol"; y por otro, la de darle consistencia literaria a un poemario que lo ve precipitándose a un abismo de cursilerías y, lo peor, arriesgando su propia autoría a la ridiculez del "narciso y medio borracho de podesía", como De Rokha le reclamará (Cit. en Zerán 171). Así, Neruda decide ejercitar las dos matemáticas, las sociales y estéticas, trocando la desesperación en planificación y anteponiendo la ingeniería estilística a la mera exorcización emocional (de hecho, sintetiza en una muchacha, todas). De este modo, el vate termina publicando en Veinte Poemas de Amor y Una Canción Desesperada -por parentela temática-, un segundo Crepusculario, pero ahora medido y contenido, cuidadamente hábil y escrupuloso, un "escrupulario". Desde sus primeras tentativas, cuando le confidencia epistolarmente a Alone la preparación de "un nuevo libro: 'Doce Poemas de Amor y una Canción Desesperada"', Neruda se muestra pudoroso, solicitándole al crítico: "No me hable mal del título. Son mi obra restante y simultánea a Crepusculario" (Cit. en Fernández 4).

Depurado y aumentado a veinte los "poemas de amor", Neruda desplaza su faena del contenido al continente. Conmina al ya envejecido poeta Augusto Winter para que le transcriba a máquina todo el libro. Sus exigencias no son meramente mecanográficas, sino también plásticas:

Insistí que éste fuera copiado en papel de estraza en formato cuadrado. También decidí que los bordes de las páginas debieran ser dentados, para lo cual el pobre don Augusto, víctima de mis caprichos, haciendo presión con el serrucho sobre el papel, dejaba cada página maravillosamente dentada (...). Más tarde, el editor conservó el formato cuadrado de mis originales, promoviendo así una pequeña 
revolución en los libros de poesías de aquel tiempo (Cit. en Olivares 109-110).

En efecto, en las primeras semanas de otoño de 1924, el escritor Eduardo Barrios actúa como intermediario frente al editor Carlos George Nascimento para publicar el libro. Transcurridos unos días, el propio Nascimento llama a Neruda para decirle: "Muy bien, publicaremos su obrita" (Neruda, Obras 544). En junio de 1924, a un mes del cumpleaños número 20 del autor, aparece el libro con 96 páginas sin numerar.

Sin embargo, su tesón curatorial, su "escrupulario", lo hace volver al contenido y al continente en 1932, fecha en que decide reeditar la obra, encargándole a Alberto Rojas Jiménez la diagramación y viñetas ${ }^{5}$. Allí emprende una segunda cirugía, mayor y a corazón aún más cerrado. Sustituye íntegramente el poema $\mathrm{N}^{\circ} 9$ de la edición de 1924 -conocido bajo el título de "El Prisionero"- por un poema sofisticado y en sincronía con la revolución estética de las primeras vanguardias, cuya cripticidad inicial muestra la complicidad con una audiencia más aggiornada: "Ebrio de trementina y largos besos, // estival, el velero de las rosas dirijo, // torcido hacia la muerte del delgado día" (39). Varias décadas más tarde, el poeta confiesa y describe parte del fuego en la cocina escritural de Veinte Poemas...recordando las misivas críticas de Sabat Ercasty. Neruda se memoriza rotundo: "Estaba equivocado. Debía desconfiar de la inspiración. La razón debía guiarme paso a paso por los pequeños senderos (...). Rompí muchos originales, extravié otros (...)” (Neruda, Confieso 70); “(...) reduje estilísticamente, de manera deliberada, mi expresión. El resultado fue mi libro Veinte Poemas de Amor y Una Canción Desesperada (Neruda, Obras 559).

\section{II. “RESILENCIA” EN LA TIERRA}

Especialistas en la obra nerudiana han trabado disputas exegéticas sobre los sedimentos o, más exactamente, sobre el légamo presente en la llamada "época azul" del vate - donde se encuentran sus primeros libros, como el citado Crepusculario, Tentativa del hombre infinito (1926); El hondero

5 El relativo desconocimiento de este hecho se debe a que Jiménez no acostumbraba a firmar su obra visual con su nombre, "sino con una copa y una botella de vino, y otras veces, casi siempre, con el nombre de Sergio, su hijo" (Plath 255). 
entusiasta (1933) y, claro está, Veinte Poemas de Amor...- para dotar de causalidad a la aparición de lo que se considera un parteaguas de la poesía hispanoamericana y universal, como lo son la publicación deslumbrante y renovadora de Residencia en la Tierra I y II (1933/1935) y, posteriormente, de Canto General (1950). En consecuencia, la valoración de esta primera etapa de la poesía del vate está relegada a la mensura de su estatus mimético con el modernismo finisecular o, más felizmente, a la microscopía de sus versos como eslabón precario - un Neruda no nato- en relación con sus obras cumbres, siempre posteriores. Curiosamente, Veinte Poemas... tempranamente niega y se resiste, no tanto a la evidencia empírica, como a la futilidad de dicha empresa analítica. Ello, debido a que la recepción de la obra hizo eclosionar a ese supuesto embrión en un Neruda ya maduro, ya fundamental, que ensombrece la criba disciplinante. Así pues, Veinte Poemas... se boleriza, se rocanrroliza, es decir, se pluraliza y populariza antes de la irrupción de la industria cultural masiva y segmentada en América Latina. Su oralidad, anclada en la memoria social, la convierte en un bien simbólico pop por su reproducibilidad: mucho de los poemas son un hit en un álbum -libro/disco- recursivo, en una época precariamente alfabetizada y fundamentalmente mnemotética (la ley de Instrucción Primaria Obligatoria se había aprobado recién en 1920). Doblegada la crítica periodística -Neruda da respuesta pública a las debilidades del libro apuntadas por Alone, Ricardo Latcham, Alfonso Escudero y Mariano Latorre ${ }^{6}$-, la música del libro se regó incontenible en la escucha social, apareciendo solo un año después de la segunda edición -1932- una tirada pirata en Buenos Aires, de amplia difusión y con sucesivas reediciones en 1933, 1934 y $1938^{7}$ que proyectó los Veinte Poemas ... a la fama internacional. En rigor, un longplay, un larga duración, antes de la democratización del acetato, de la expansión de la radiodifusión y de la irrupción de Lucho Gatica o Frank Sinatra, con veinte baladas contagiosas y un poema-epílogo no bailable. “(...) Entonces entró Eva hablando en español en un librito de bolsillo nacido en Chile (...) Para enseñarnos que un amor de poeta latinoamericano podía leerse y escribirse hic et nunc (...)", recordaría Julio Cortázar (Loyola, Neruda 166). Más aún, una sola casa editorial -Losada- celebrará en junio de 1961 el millón de

6 Neruda, Pablo. "Exégesis y soledad". Diario La Nación. (20 de agosto de 1924).

7 Nos referimos a las editadas en Buenos Aires por Editorial Tor. 
libros impresos y, en diciembre de 1972, con la $17^{\mathrm{a}}$ edición, conmemorará la suma de dos millones de ejemplares de la obra.

Las y los poetas que le acompañan, aquejados por un incipiente vanguardismo mimético/hermético y un acolchado tardo-romanticismo, se verán imposibilitados de mediatizarse e industrializarse simbólicamente, sus obras no dan con la tesitura emocional que vocean en la intimidad las nuevas clases medias y populares en América Latina. Entonaciones anómalas que Neruda oye y reproduce; notas pendulares, cuyo vaivén recuerda el ritmo modernista - el Azul de Darío se cuela aún- pero que acunan, en la melopea hipnótica, acoples imprevistos y sobresaltos métricos de la primera vanguardia. Ruta intermedia, para nada inocente, que escarcea y rehuye por igual, tanto de Huidobro y de De Rokha, como de las dos cohortes anteriores -poetas de 1900 y 1914-, como Pedro Antonio González, Miguel Magallanes Moure, Víctor Domingo Silva, Max Jara, Gabriela Mistral o Pedro Prado. Aunque amplifica -los Veinte poemas... no son los Veinte poemas para ser leídos en el tranvía (1922) de Oliverio Girondo-, la pluma de Alone detecta, auguralmente, parte de las pretensiones de la obra:

Abramos sin pasión su segundo volumen poético [Veinte Poemas de Amor ...]. Parece más raro y menos accesible que el primero... Aquí domina cierta especie de sequedad entrecortada, casi dolorosa, una violencia de expresión, hija tal vez del excesivo afán de novedad. (...) El poeta quiere separarse a toda costa de los otros, los viejos, los de ayer, los de anteayer y corta amarras, bate el ala al viento, trata de alejarse y huir (Alone $\mathrm{s} / \mathrm{n}$ ).

Neruda responde, reconoce y alega que en diez años solitarios de oficio, se le han adherido "ritmos diversos, corrientes contrarias", "sin hallar lo perdurable, porque no existe" (Neruda, Exégesis $s / n$ ). Desde la ira, De Rokha no se equivoca del todo a propósito de Veinte Poemas...:

Singulariza a estos poetas del medio ambiente, a estos poetas a la moda, a estos poetas siempre a la moda, la maña técnica, el truco, la utilización admirable de la retórica del instante, de la poética del instante, del "acento" del momento. (...) Y así, aquel verso tonto, aquel verso bobo de demencia con su matraca malvada y asonantada, va acunando el material hospiciano, el saldo, el complejo saldo de imbecilidad bailable que posee el individuo (Cit. en Zerán 171172). 
"Imbecilidad bailable", cuyo beat -para irritación del autor de Los Gemidosmueve incontenible las palmas y el cuerpo social, como pocos ritmos lo habían hecho. Maestro, Neruda y su estratagema enrarecida de alejandrinos, endecasílabos y verso libre, asesta un disco de platino universal, utilizando en su poemario, velada, pero con lujo, nada más ni nada menos que 26 veces la palabra "alma", excomulgada ya en el diccionario de la poesía.

El resultado es anómalo y riesgoso si se considera la ruptura acaecida en el horizonte socio-estético de la poesía chilena de las primeras décadas del siglo XX en relación con la del siglo XIX. La autonomización del campo literario como espacio de producción simbólica de "imaginación" en los primeros años de 1900 -es decir, su deslinde con el periodismo, el folletín, el ensayo político o historiográfico (Catalán 118-140), había puesto en entredicho el "gusto oligárquico" que de la mano de Núñez de Arce, Campoamor, Bécquer, Gutiérrez Nájera, fundían lo poético con lo declamatorio y lo estético con lo patético. La bohemia rebelde, articulada en torno a la revista de la Federación de Estudiantes Claridad, el centro político-literario Francisco Ferrer, el café Los Inmortales o los bares de calle Bandera, San Pablo, Phillips, habían desterrado los afanes "romanticones" y la "literatura de confitería" en diálogo, fundamentalmente, con la literatura rusa y el simbolismo y surrealismo francés. No obstante, Neruda Con Veinte Poemas ... transporta de una manera oblicua la herencia decimonónica, revitalizando la semilla de la oralidad e instalando la arritmia de un compás como poesía de uso, ya en la domesticidad o en el cenáculo público de aquellos que se duelen y se aman. Así, Veinte Poemas..., en el continuum o en la autonomía de la obra nerudiana, es resilente ${ }^{8}$. En primer término -y desde su génesis-, porque materializa y reconvierte la mera tribulación biográfica -sentimental- del autor en un objeto estético que capitaliza su talento y tesón escritural para visibilizarlo como poeta. En segundo término $-\mathrm{y}$ crucial en relación con este último

8 El término resilencia o resiliencia (del latín "resilio", que significa volver atrás, volver de un salto) es usado por las ciencias físicas para describir la habilidad que posee un metal de absorber un impacto, tolerar temperaturas altas o sufrir algún cambio deformador y luego poder recobrar su forma y sus propiedades originales. Contemporáneamente se ha extendido, primero, a la sicología y seguidamente a las ciencias sociales, para comprender la flexibilidad social adaptativa como respuesta a diversos tipos de exclusión y riesgo social, así como adversidades o acontecimientos traumáticos (Vgr. Grotberg E. 2002). Aquí ampliamos metafóricamente el sentido del vocablo para aplicarlo no solo a la autoría sino también a una obra literaria que sancionada o excluida tiene la capacidad adaptativa de sobreponerse y fortalecerse ante dichos fenómenos. 
apartado-, la obra se sobrepone a la sanción estética de sus contemporáneos, al castigo del filtro especializado y a la subordinación estética. De este modo Veinte Poemas ... pareciera contener dispositivos resilentes que actualizan su entereza ante las lecturas adversas y que explican su impacto formativo en varias generaciones de lectores en el mundo a lo largo del siglo XX. Uno de estos dispositivos, por ejemplo, es el que neutraliza la instrumentalización identitaria: el intento de imponer a Neruda como el santón mayor de una chilenidad ensimismada, soslayando el "esperanto" que subyace en éste, su gran libro apátrida. Curiosa trayectoria para un poemario que comenzó como una "obrita" para su editor y que tuvo un efecto milimétricamente contrario en la "audiencia" global a lo que predicara el metódico e instruido crítico Ricardo A. Latcham: "Estos poemas... desesperan antes de que el lector llegue a entonar la canción" (Cit. en Olivares 28).

\section{BIBLIOGRAFÍA}

Alone. “Crónica Literaria”. La Nación (3 de agosto de 1924): s/p.

Catalán, Gonzalo: "Antecedentes sobre la transformación del campo literario en Chile entre 1890 y 1920 ”. Brunner, Joaquín y Gonzalo Catalán. Cinco estudios sobre cultura y sociedad. Santiago: FLACSO, 1985. 70-175.

Fernández, Sergio. Cartas de Amor de Pablo Neruda. Barcelona: Rodas, 1974.

Gonzalez, Yanko. “Que los Viejos se Vayan a Sus Casas'. Juventud y Vanguardia en América Latina”. Movimientos Juveniles. De la globalización a la antiglobalización. Coord. Feixa, Carles et al. Barcelona: Ariel, 2002. 59-91.

Loyola, Hernán. Neruda. La biografia literaria. Barcelona: Seix Barral, 2006.

"Notas". Neruda Pablo. Veinte poemas de amor y una canción desesperada. Buenos Aires: Debolsillo, 2003.

Neruda, Pablo. Veinte Poemas de Amor y Una Canción Desesperada. Santiago: Nascimento, 1924

Veinte Poemas de Amor y Una Canción Desesperada. 1932. Santiago: Ediciones UDP, 2008.

za.

Conferencia en la Universidad de Chile, enero de 1954. Archivo Jorge Sanhue-

"Poesía de su Silencio". Revista Zig-Zag. 985 (5 de enero de 1924): s/p.

Para Nacer he Nacido. Barcelona: Seix Barral, 1977.

Confieso que he vivido. Buenos Aires: Losada, 1986.

“Exégesis y soledad". Diario La Nación (20 de agosto de 1924): s/p.

"Mariano Latorre, Pedro Prado y mi propia sombra". Obras Escogidas: Santiago:

Andrés Bello, 1971. 
"Exégesis y soledad", Diario La Nación (20 de agosto de 1924): s/p.

Olivares, Edmundo. Pablo Neruda: Los caminos de Oriente. Tras las huellas del poeta itinerante (1927-1933). Santiago: Lom, 2000.

Plath, Oreste. Alberto Rojas Jiménez se paseaba por el alba. Santiago: Centro de Investigaciones Barros Arana, 1994.

Schopf, Federico. De la vanguardia a la antipoesía. Ensayos sobre la poesía en Chile. Santiago: Lom, 2000.

Zerán, Faride. La guerrilla literaria. Santiago: Bat, 1992.

Grotberg E. "Nuevas tendencias en resiliencia". Resiliencia. Descubriendo las propias fortalezas. Melillo A. y E. Suárez comp. Buenos Aires: Paidós, 2002. 27-29. 